\title{
Cervical Rib Causing Occlusion of the Subclavian Artery and Thoracic Outlet Syndrome
}

\author{
Brandon R Erickson, Michael R Go and Patrick S Vaccaro*
}

Division of Vascular Diseases and Surgery, The Ohio State University, USA

\begin{abstract}
Purpose: To present an unusual case of a cervical rib as a cause of subclavian artery occlusion and thoracic outlet syndrome.

\section{Procedures: Case report}

Results: A 39-year-old female presented to the emergency room with a 2-day history of unilateral headache, facial tingling, and slurred speech, along with a 2-month history of left upper extremity weakness and coolness of the left hand. A stroke workup that included carotid duplex ultrasonography revealed findings suggestive of left subclavian occlusion, later confirmed on CT angiography. Neurologic workup suggested migraine, rather than ischemia, as the cause of headache; however, the subclavian occlusion prompted further investigation, including a chest radiograph that revealed bilateral cervical ribs. The patient was taken to surgery where her left cervical rib was excised and the chronically occluded left subclavian artery was found to have significant post-stenotic dilatation. Given that the chronic nature of her left upper extremity symptoms were not limiting, the decision was made to not undertake bypass. Recommendation was made to remove her right cervical rib prophylactically at a future date.
\end{abstract}

Conclusions: Cervical ribs are a rare cause of vascular thoracic outlet syndrome, with compression leading to post-stenotic dilatation and symptoms of ischemia in the involved extremity.

Keywords: Vascular thoracic; Ischemia; Subclavian thrombosis

\section{Introduction}

Cervical ribs were first noted by Galen in the second century A.D., and by Vesalius in the 16th century [1]. The incidence of cervical ribs is estimated at two percent of the general population [2]. Subclavian thrombosis as a result of cervical rib compression was described as early as 1927 by Symonds in the case of a patient who developed hemiplegia due to an embolism [3]. In 1956, Peet used the term thoracic outlet syndrome to describe upper limb symptoms arising from neurovascular compression in the interscalene triangle [4]. A recent retrospective analysis revealed that as many as two-thirds of patients with arterial compression at the thoracic outlet may have associated bone anomalies, cervical ribs being chief among these, followed by anomalies of the first rib [5]. Symptoms of upper extremity ischemia, paresthesias, and hand coldness are common [6,7].

There are still few detailed reports of cervical ribs as a cause of subclavian artery occlusion and thoracic outlet syndrome. This case report seeks to provide a clinical correlation with surgical findings and radiographic imaging.

\section{Case Report}

A 39-year-old female presented to the emergency room with a 2-day history of shooting pain in left side of her head, along with dull achy headache pain, partially relieved by ibuprofen. She also reported a 20-minute episode of tingling of the left face earlier that day, and a brief episode of slurred speech. Prior to this she reports no prior history of stroke symptoms, facial numbness, headache, clotting or bleeding disorders. She had a history of irritable bowel syndrome and left ulnar neuropathy, for which she was taking hyoscyamine and gabapentin. Review of systems revealed a headache, left upper extremity weakness, and a cold sensation and tingling in the left hand. She was otherwise negative for lateralizing symptoms or visual field deficits. Her family history was negative for seizures, bleeding clotting, or vascular disorders. She denied any use of alcohol, tobacco or illicit drugs.

On physical examination, blood pressure was not obtainable from her left upper extremity and her left hand felt slightly cooler than right. Blood chemistries, lipid studies, and coagulation studies were all normal. She did not have a palpable left radial or ulnar pulse.

Given her episode of facial tingling and reported episode of slurred speech, a stroke evaluation was undertaken. CT and MRI of the head showed no acute intracranial process, and a transthoracic echocardiogram was negative. However, a carotid duplex revealed findings suggestive of occlusion of the left subclavian artery and reduced vertebral flow on the left as shown in Figures 1-3. A CT angiogram confirmed the presence of left subclavian and vertebral artery occlusion. Upon further workup at an outpatient vascular clinic, the patient was found to have protrusions in both supraclavicular fossae suggestive of cervical ribs. This clinical suspicion was later confirmed via chest X-ray. A concurrent neurologic workup strongly suggested that her headache at initial presentation was a migraine and unrelated to ischemia. The recommendation was made for the patient to undergo surgery for excision of the left cervical rib with possible thrombectomy or arterial interposition grafting as shown in Figures 4 and 5.

*Corresponding author: Patrick S Vaccaro, Division of Vascular Diseases and Surgery, The Ohio State University, USA, Tel: 614 2938536/614 3068033; E-mail: Patrick.Vaccaro@osumc.edu

Received April 17, 2015; Accepted May 19, 2015; Published May 21, 2015

Citation: Erickson BR, Go MR, Vaccaro PS (2015) Cervical Rib Causing Occlusion of the Subclavian Artery and Thoracic Outlet Syndrome. J Vasc Med Surg 3: 202. doi:10.4172/2329-6925.1000202

Copyright: (c) 2015 Erickson BR, et al. This is an open-access article distributed under the terms of the Creative Commons Attribution License, which permits unrestricted use, distribution, and reproduction in any medium, provided the original author and source are credited. 
Citation: Erickson BR, Go MR, Vaccaro PS (2015) Cervical Rib Causing Occlusion of the Subclavian Artery and Thoracic Outlet Syndrome. J Vasc Med Surg 3: 202. doi:10.4172/2329-6925.1000202

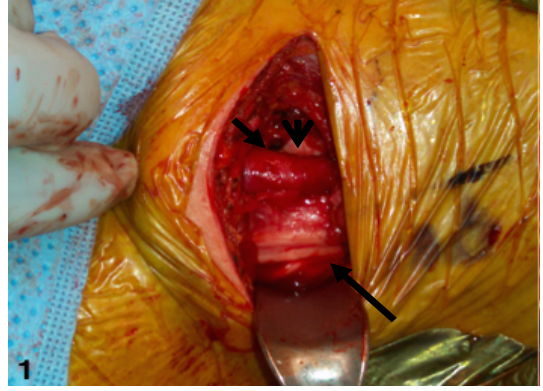

Figure 1: Left subclavian artery (short arrow) and brachial plexus (long arrow) exposed with cervical rib partially visible behind it (arrowhead).

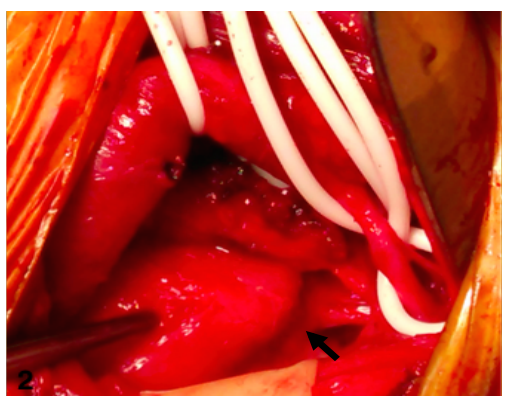

Figure 2: Subclavian artery and brachial plexus retracted to show connection between cervical rib and first rib (short arrow).

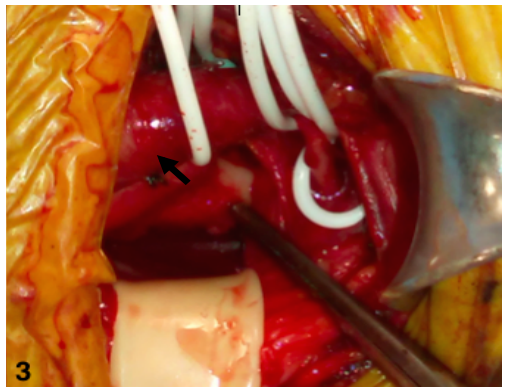

Figure 3: Dilatation of subclavian artery (short arrow) with cervical rib visible behind it. A firm pulsatile mass was felt on palpation.

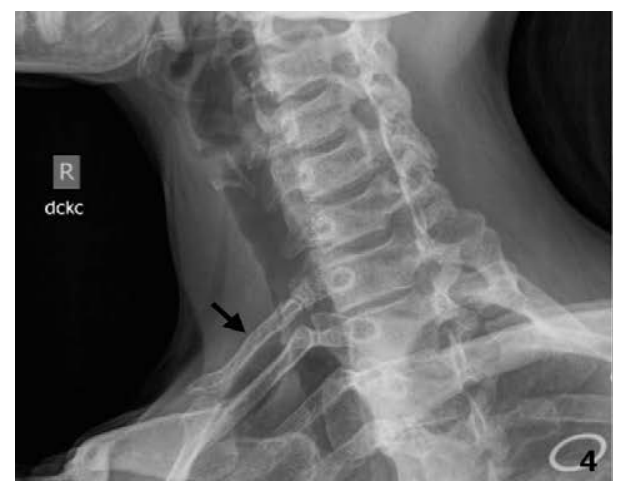

Figure 4: Radiographs showing left cervical rib before excision.

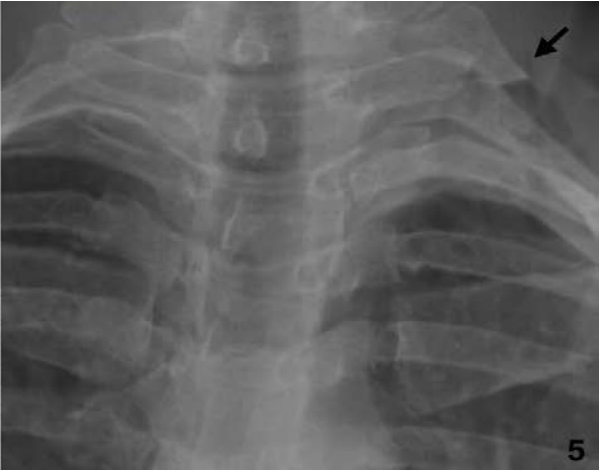

Figure 5: Radiographs showing left cervical rib after excision.

Intraoperatively, a large subclavian artery aneurysm was found just anterior to the cervical rib, and the cervical rib was fused to the first rib just underneath the subclavian artery. On inspection, the subclavian artery aneurysm appeared to result from post-stenotic dilatation stemming from compression by the cervical rib. Immediately proximal to the dilatation, a water hammer pulse was dopplered, with loss of pulse in the artery distal to the rib extending into the axillary artery.

Given that the patient's left extremity symptoms were chronic in nature and had not interfered with her ability to work, the decision was made to forgo thrombectomy or bypass.

\section{Discussion}

Patients with cervical ribs resulting in stenosis often remain asymptomatic untilpost-stenotic dilatation with thrombus formation and embolization occurs. The pathogenesis of post-stenotic dilatation is not fully understood, but likely results from stasis, increased lateral pressure, cavitation, abnormal shear stresses and turbulence [8,9].

Based on a recent review, the role of cervical ribs in causing thoracic outlet syndrome may be underappreciated [5]. Cervical ribs should be considered in any patient presenting with thoracic outlet syndrome, and their presence can be suggested by physical exam findings on palpation of the supraclavicular fossae with subsequent confirmation via cervical radiographs.

In patients with bilateral cervical ribs who have already had one of their cervical ribs removed due to symptomatic occlusion, consideration should be given for prophylactic removal of the contralateral cervical rib. Some practitioners argue for regular surveillance imaging of the asymptomatic side to monitor for the development of subclinical arterial occlusion in these patients [10].

\section{Acknowledgements}

The authors thank the Division of Vascular Diseases and Surgery at The Ohio State University Wexner Medical Center.

\section{References}

1. Adson AW, Coffey JR (1927) Cervical rib: a method of anterior approach for relief of symptoms by division of the scalenus anticus. Ann Surg 85: 839-857.

2. Viertel VG1, Intrapiromkul J, Maluf F, Patel NV, Zheng W, et al. (2012) Cervical ribs: a common variant overlooked in CT imaging. AJNR Am J Neuroradiol 33 : 2191-2194.

3. Symonds CP $(1927)(2,3)$ Cervical Rib: Thrombosis of Subclavian Artery Contralateral Hemiplegia of Sudden Onset, probably Embolic. Proc R Soc Med 20: $1244-1245$. 
Citation: Erickson BR, Go MR, Vaccaro PS (2015) Cervical Rib Causing Occlusion of the Subclavian Artery and Thoracic Outlet Syndrome. J Vasc Med Surg 3: 202. doi:10.4172/2329-6925.1000202

Page 3 of 3

4. Peet RM, Henriksen JD, Anderson TP, Martin GM (1956) Thoracic-Outlet Syndrome: Evaluation of a Therapeutic Exercise Program. Proc Staff Meet Mayo Clin 31: 281-287.

5. Criado E, Berguer R, Greenfield L (2010) The spectrum of arterial compression at the thoracic outlet. J Vasc Surg 52: 406-411.

6. Hugl B, Oldenburg WA, Hakaim AG, Persellin ST (2007) Unusual etiology of upper extremity ischemia in a scleroderma patient: thoracic outlet syndrome with arterial embolization. J Vasc Surg 45: 1259-1261.

7. Bearn P, Patel J, O'Flynn WR (1993) Cervical ribs: a cause of distal and cerebral embolism. Postgrad Med J 69: 65-68.
8. Rodbard S, Ikeda K, Montes M (1967) An analysis of mechanisms of post stenotic dilatation. Angiology 18: 349-367.

9. Crotty TP (1994) Poststenotic dilatation in arteries and the role of turbulence. Med Hypotheses 42: 367-370.

10. Sanders RJ, Hammond SL (2002) Management of cervical ribs and anomalous first ribs causing neurogenic thoracic outlet syndrome. J Vasc Surg 36: 51-56. 